\title{
Thresholds of Basal- and Calcium-Stimulated Calcitonin for Diagnosis of Thyroid Malignancy
}

\author{
Authors \\ Mara Băetu1, $2 \mathbb{1}^{\mathbb{D}}$, Cristina Alexandra Olariu¹, Cristina Stancu¹, Andra Caragheorgheopol1, 2, Dumitru loachim¹, \\ Gabriel Moldoveanu ${ }^{1}$, Cristina Corneci ${ }^{1}$, Corin Badiu ${ }^{1,2}$
}

\author{
Affiliations \\ 1 “C.I. Parhon" National Institute of Endocrinology, \\ Bucharest, Romania \\ 2 "Carol Davila" University of Medicine and Pharmacy, \\ Bucharest, Romania
}

Key words

calcitonin, stimulation test, thresholds, cut-off, medullary

thyroid carcinoma

received 16.07 .2021

accepted after revision 27.09.2021

published online 22.10 .2021

Bibliography

Horm Metab Res 2021; 53: 779-786

DOI 10.1055/a-1661-4420

ISSN 0018-5043

(C) 2021. Thieme. All rights reserved.

Georg Thieme Verlag KG, Rüdigerstraße 14,

70469 Stuttgart, Germany

Correspondence

Mara Băetu M.D., Ph.D. Student

"C. Davila" University of Medicine and Pharmacy

"C.I. Parhon" National Institute of Endocrinology

34-38 Aviatorilor Bvd

011863 Bucharest

Romania

Tel.: +40/741/498 229

mara.baetu@drd.umfcd.ro

\section{ABSTRACT}

Since medullary thyroid carcinoma is an aggressive cancer, it is important to have an early detection based on stimulated calcitonin (CT), especially when basal-CT is slightly elevated. The objective of this work was to set specific thresholds for basal-CT- and calcium-stimulated calcitonin for prediction of thyroid malignancy in female population. The study included 2 groups: group A-women with elevated basal-CT (>9.82 pg/ $\mathrm{ml}$ ) and group B-women with normal basal-CT (control group). After calcium stimulation test precise protocol, histopathological reports of those that required surgery were correlated with both basal and stimulated calcitonin. The best basal and stimulated calcitonin cut-offs for distinguishing female patients with medullary thyroid carcinoma or C-Cell-hyperplasia from other pathologies or normal cases were: $12.9 \mathrm{pg} / \mathrm{ml}$, respectively $285.25 \mathrm{pg} / \mathrm{ml}$. For basal-CT above $30 \mathrm{pg} / \mathrm{ml}$, malignancy was diagnosed in 9/9 patients (100\%): 9 MTC. For stimulated calcitonin above $300 \mathrm{pg} / \mathrm{ml}$, malignancy was diagnosed in 17/21 patients ( $80.95 \%): 12$ MTC and 5 papillary thyroid carcinomas. The smallest nodule that proved to be medullary thyroid carcinoma had only $0.56 / 0.34 / 0.44 \mathrm{~cm}$ on ultrasound, with no other sonographic suspicious criteria. In conclusion, we have identified in Romanian female population basal and stimulated calcitonin thresholds to discriminate medullary thyroid carcinoma or C-Cell-hyperplasia from other cases. We recommend thyroid surgery in all women with stimulated calcitonin above $285 \mathrm{pg} / \mathrm{ml}$. Further studies on larger groups are necessary to establish and confirm male and female cut-offs for early diagnosis of medullary thyroid carcinoma, and interestingly, maybe for macro-papillary thyroid carcinomas alike. The calcium administration has minimum side-effects, but continuous cardiac monitoring is required.

\section{Introduction}

Medullary thyroid carcinoma (MTC) is a tumour derived from the parafollicular $\mathrm{C}$ cells of the thyroid gland. According to current revised guidelines, MTC is diagnosed usually after fine needle aspiration biopsy (FNAB) and immunocytochemistry with determination of calcitonin (CT), carcinoembryonic antigen (CEA), and chromogranin A (CgA) or by histopathology analysis after surgery [1]. Genetic testing for RET mutations can predict an early diagnosis. The diagnosis is also suspected at very high levels of basal CT (bCT). The guidelines mention that a
bCT $>100 \mathrm{pg} / \mathrm{ml}$ reveals a very high risk of MTC [1-3]. However, discreetly elevated values are controversial. There are even controversies about CT measurement in the screening of a thyroid nodule/polynodular goitre. Despite the fact that American Thyroid Association (ATA) has not disclosed a statement for or against CT measurement in thyroid nodule(s) screening, some authors have stressed out that CT dosage is important for an early diagnosis of MTC [2-8]. More than that, some studies reported that $C T$ dosage has a greater diagnostic sensitivity and specificity than FNAB [1,9]. 
FNAB is not required for nodules $<1 \mathrm{~cm}$ without high suspicion on ultrasonography [10]. Thus, when is not the case to perform a FNAB, if CT is not dosed, microMTC can be overlooked. The natural evolution of microMTC is still unknown and a delay in the diagnosis and surgery may worsen the prognosis [11].

Calcium ( $\mathrm{Ca}$ ) administration has been shown to increase the sensitivity of CT levels [1] and several authors reported stimulated CT (sCT) thresholds for diagnosis of MTC [12-16], Interestingly, CT does not increase by stimulation with $C a$ in patients with various non-thyroid malignancies [1]. The ATA guidelines for MTC do not specify any cut-offs for bCT or SCT for the diagnosis of MTC or for therapeutic decision, but recommends that individual laboratories set their own reference thresholds [1].

There are gender specific differences regarding serum CT $[1,12,16,17]$. It is not exactly known what causes the gender differences, but some reports note a bigger C Cell mass in men $[1,18]$. This triggers the need to establish different cut-offs for men and women regarding the diagnosis of MTC.

Since MTC is an aggressive cancer, it is very important to have an early detection based on SCT values, especially when bCT are slightly elevated, because the cure rates are higher only when the resection of the thyroid tumour mass and of any local and regional metastases is complete. The prognosis is better when the disease is detected in localized stages [19].

\section{Objective}

To set in our laboratories gender specific thresholds for bCT and Ca-sCT for the Romanian female population, with high specificity and sensitivity for prediction of MTC, as guidelines recommend.

\section{Patients and Methods}

\section{Design}

Our study was designed as an analytical prospective longitudinal cohort study between June 2018 and July 2020. The study included 2 groups: group A: women with elevated bCT and group B: women with normal bCT (control group), as per criteria detailed below.

\section{Ethics Approval}

The protocol was previously defined and precisely followed. The study was approved by the Ethics Committee of Scientific Research of "Carol Davila" University of Medicine and Pharmacy, Bucharest, Romania, No. 161/PO-35-F-03. Every patient gave their approval by completing an informed consent. Afterwards, a clinical examination and a set of investigations were performed on each patient.

\section{Patients}

Inclusion criteria group A

- Female patients with a history of solitary thyroid nodule or polynodular goitre, that have elevated levels of bCT ( $>9.82 \mathrm{pg} / \mathrm{ml}=$ upper limit of normal [UPN] for Cobase601).
Inclusion criteria group B (control group)

- Female patients with history of solitary thyroid nodule or polynodular goitre and normal bCT values, that will undergo thyroidectomy for clearly indications (voluminous nodule/ multinodular goitre, compressive nodule/multinodular goitre or conforming to the Bethesda classification after FNA).

\section{Exclusion criteria for both groups}

- Hyper-/hypocalcaemia, hypo-/hyperkalaemia;

- Chronic kidney disease stages IV-V;

- Cyanogenic congenital heart diseases, arrhythmogenic heart diseases, prolonged PR or QT interval, grade II-III atrioventricular block, heart frequency $>110 /$ min or $<40 /$ min, history of myocardial infarction;

- Pregnancy.

The following tests were required to establish whether the patient had any exclusion criteria: serum ionogram (total Ca, ionized Ca, potassium); serum creatinine and urea with glomerular filtration rate estimation using MDRD formula (Modification of Diet in Renal Disease study); cardiology check-up with blood pressure (BP), heart rate (HR), and 12 leads electrocardiogram (ECG).

Group A included 74 female patients with elevated bCT, median age $=43.5 \pm 13$ years (range: $19-70$ ). Five patients performed the test several times in dynamic, at least 3 months apart, with a total of 80 stimulations tests for this group. Group B (control group) included 31 female patients with normal bCT, median age $=50 \pm 15.51$ years (range: $23-78$ ), with a total of 31 stimulations tests for this group.

\section{Calcitonin Stimulation Test Protocol}

\section{Pre-test}

First, all patients were apprised regarding possible side-effects that were also mentioned in the written informed consent. Second, on each upper limb two cannulas were inserted (peripheral venous pathways). One cannula was for Ca infusion and the other one for blood collection for $\mathrm{CT}$ samples. The first $\mathrm{CT}$ sample was collected before $\mathrm{Ca}$ administration. Before the test, the ECG and BP monitoring have been started.

\section{Test}

The Ca stimulation test was performed in the intensive care unit (ICU) and the Ca was always injected by the anaesthesiologist. The protocol used for CT stimulation consisted in intravenous (iv) administration of $2.47 \mathrm{mg}$ per ideal body weight of elemental Ca. To avoid overdosing, it was always adjusted to the patient's ideal body weight calculated with Lorentz formula: Ideal Weight $(\mathrm{Kg})=$ Height $(\mathrm{cm})-100-[$ Height $(\mathrm{cm})-150] / 2$. The type of Ca used was Ca gluconate because it had the most studies so far. The total amount of Ca gluconate was slowly injected over a period of 3-5 minutes, depending on every patient's tolerance. For that, an ongoing dialog with each patient was mandatory. After Ca administration, three more CT samples are drawn at 2, 5, and 10 minutes after the end of the injection. Each patient was further monitored with both ECG and BP during the test. 


\section{Post-test}

In order to ease Ca urinary excretion, an iv infusion with $500 \mathrm{ml}$ saline ( $\mathrm{NaCl} 0.9 \%)$ was slowly administered after Ca injection. Each patient was further monitored with both ECG and BP for another 60-180 minutes in ICU. All four CT samples (before and at 2, 5, and 10 min after $(a$ administration) were immediately sent to the laboratory for further analysis.

\section{Serum analysis}

After serum samples were centrifuged, CT was measured using an electro-immunochemiluminiscence assay (Cobase601) based on sandwich principle with monoclonal antibodies directed against human CT. This method has been standardized according to World Health Organization CT International Standard (WHO 89/620). The analyte concentration was automatically calculated, and the analyser expressed the result in $\mathrm{pg} / \mathrm{ml}$. The reported reference values by manufacturer are: $5.17-9.82 \mathrm{pg} / \mathrm{ml}$ for women. Afterwards, the CT samples were aliquoted and stored at $-20{ }^{\circ} \mathrm{C}$.

\section{Management}

Depending on the test results, based on the experience published in the literature and on our experience so far, some patients from group $A$ had a recommendation for surgery, A total of 35 women from group A had thyroidectomy. All 31 women from group B (control group) had thyroidectomy for various indications: voluminous nodule/multinodular goitre, compressive nodule/multinodular goitre or conforming to the Bethesda classification after FNA.

\section{Histopathological analysis}

For all 66 patients that had surgery, after the intervention, the tissue samples were embedded in paraffin and the blocks were further processed into thin microscopic sections. The slides were analysed by a pathologist with experience in thyroid pathology. All histopathological reports were further correlated with both bCT and SCT values.

\section{Statistical analysis}

We performed the statistical analysis using IBM SPSS Statistics version 20. For cut-offs establishment we applied Receiver Operator Characteristic (ROC) Curve. Statistical significance was considered for $p<0.05$.

\section{Results}

In our study, bCT was between 9.85-98.91 pg/ml in group A (basal hypercalcitoninaemia group), with a median of $12.56 \pm 21 \mathrm{pg} / \mathrm{ml}$, and between $0.5-9.23 \mathrm{pg} / \mathrm{ml}$ in group $\mathrm{B}$ (control group), with a median of $0.86 \pm 1.96 \mathrm{pg} / \mathrm{ml}$. Among 111 explorations studied, peak sCT was noted at 2 minutes after the end of $\mathrm{Ca}$ injection in 88 , at 5 minutes in 19 , and at 10 minutes in 4 tests. Peak sCT was between $30.6-2812 \mathrm{pg} / \mathrm{ml}$ in group $A$ with a median of $175.85 \pm 407.98 \mathrm{pg} /$ $\mathrm{ml}$, and between $1.02-167 \mathrm{pg} / \mathrm{ml}$ in group $B$ with a median of $5.82 \pm 37.15 \mathrm{pg} / \mathrm{ml}$. There was no correlation between bCT or peak sCT values and patient's weight, height, body mass index, creatinine, glomerular filtration rate and presence or level of thyroid antibodies.
In elevated bCT group (group A), among 35 women that required thyroidectomy, only $6(17.14 \%)$ had a benign report ( $\triangleright$ Table 1). The lowest bCT corresponding to MTC in this group was $9.85 \mathrm{pg} / \mathrm{ml}$.

For bCT levels between $9.82-30 \mathrm{pg} / \mathrm{ml}$, malignancy was found in 19 out of 26 female patients (73.07\%): 8 mMTC (MTC $<1 \mathrm{~cm}), 3$ macroPTC (papillary thyroid carcinoma $>1 \mathrm{~cm}$ ) and $8 \mathrm{mPTC}$ (papillary thyroid carcinoma $<1 \mathrm{~cm}$ ). For bCT above $30 \mathrm{pg} / \mathrm{ml}$, malignancy was diagnosed in 9 out of 9 female patients (100\%): 7 mMTC and 2 macroMTC (MTC>1 cm). The lowest sCT corresponding to MTC in this group was $98.1 \mathrm{pg} / \mathrm{ml}$. For sCT between $100-300 \mathrm{pg} /$ $\mathrm{ml}$, malignancy was found in 8 out of 11 female patients $(72.73 \%$ ): 4 mMTC, 3 mPTC and 1 macroPTC. For sCT above 300 pg/ml, malignancy was diagnosed in 17 out of 21 female patients ( $80.95 \%$ ): 10 mMTC, 2 macroMTC, 3 mPTC, and 2 macroPTC ( $\triangleright$ Table 1).

In normal bCT group (group B), among 31 women that had thyroidectomy, 20 (64.51\%) had a benign report ( $\triangleright$ Table 2 ). Surprisingly, a bCT of only $2.9 \mathrm{pg} / \mathrm{ml}$, that rose up just to $42.66 \mathrm{pg} / \mathrm{ml}$ after Ca corresponded to a mMTC ( $\triangleright$ Table 2 ).

The best bCT cut-off for distinguishing female patients with MTC or CCH from other pathologies or benign cases was: $12.9 \mathrm{pg} / \mathrm{ml}$, with a sensitivity of $84.2 \%$ and specificity of $76.6 \%$, AUC (area under the curve) $0.895, \mathrm{Cl}$ (confidence interval): 0.816-0.973, $\mathrm{p}<0.001$. The best sCT cut-off for distinguishing female patients with MTC or CCH from other pathologies or normal cases was: $285.25 \mathrm{pg} / \mathrm{ml}$, with a sensitivity of $73.7 \%$ and specificity of $83 \%$, AUC 0.886, Cl: 0.804-0.967, p<0.001 ( Fig. 1 and 2).

The smallest nodule in our study that proved to be MTC was a solitary hypoechoic solid nodule of only $0.56 / 0.34 / 0.44 \mathrm{~cm}$ on ultrasound, with no other sonographic suspicious criteria. The patient (No. 24, - Table 1) was 29 years old, with a bCT of $29.19 \mathrm{pg} /$ $\mathrm{ml}$ that stimulated up to $347.5 \mathrm{pg} / \mathrm{ml}$ and proved after surgery to carry Val804Met RET mutation. One other patient (No. 12, > Table 1) with MTC diagnosed after stimulation test was identified with RET gene mutation (Val804Leu) and one (No. 29, > Table 1) had a variant with uncertain significance (Ala639Thr). Both of them had nodules that were also under $1 \mathrm{~cm}$ on thyroid ultrasonography.

\section{Discussion}

Ca and pentagastrin $(\mathrm{Pg})$ have been the most widely used substances for stimulating CT over time. $\mathrm{Pg}$ is obsolete, it is not found worldwide and has more pronounced side effects [12, 20-22].

Several authors have defined various cut-offs for distinguishing normal cases from $C$ cell disease. Giovanella proposed a sCT below $78.5 \mathrm{pg} / \mathrm{ml}$ to be the normal threshold in healthy female subjects [13]. Kihara et al. reported as normal a sCT below $67.6 \mathrm{pg} / \mathrm{ml}$ for women and $<83.7 \mathrm{pg} / \mathrm{ml}$ for men. More than that, they mentioned that both women and men could be considered biochemically cured after total thyroidectomy at a sCT $<0.5 \mathrm{pg} / \mathrm{ml}[23,24]$. Papadakis et al. disclosed that an overall cut-off of $>17.4 \mathrm{pg} / \mathrm{ml}$ for bCT and $>452 \mathrm{pg} / \mathrm{ml}$ for sCT had the best positive predictive value and sensitivity for distinguishing CCH from MTC [15]. In 2012, Colombo et al. have defined the following gender-specific bCT and SCT cut-offs to discriminate normal and CCH cases from MTC: $>18.7 \mathrm{pg} / \mathrm{ml}$ and $>184 \mathrm{pg} / \mathrm{ml}$ for women, respectively, $>68 \mathrm{pg} / \mathrm{ml}$ and $>1620 \mathrm{pg} / \mathrm{ml}$ for men [12]. The sCT cutoffs lowered to $>32.6 \mathrm{pg} / \mathrm{ml}$ for women and $>192 \mathrm{pg} / \mathrm{ml}$ in men for the 
- Table 1 Patients from group A (elevated bCT) that had thyroidectomy $(\mathrm{n}=35)$.

\begin{tabular}{|c|c|c|c|c|c|c|c|c|c|}
\hline No. & Age & $\begin{array}{l}\text { FNAB } \\
\text { (Bethesda) }\end{array}$ & $\begin{array}{l}\text { bCT } \\
\left(0^{\prime}\right)\end{array}$ & $2^{\prime}$ & $5^{\prime}$ & $10^{\prime}$ & HP & Tumour Foci $(\mathrm{cm})$ & Staging system \\
\hline 1 & 41 & - & 9.85 & 576 & 274 & 121 & mMTC & $0.7 / 0.6$ & PT1aN0 \\
\hline 2 & 29 & II & 11 & 69.8 & 47.6 & 29.3 & mPTC & $0.1 / 0.1$ & PT1aN0 \\
\hline 3 & 28 & ॥ & 11.13 & 145 & 137.6 & 111.6 & mPTC & $0.1 / 0.1$ & PT1aN0 \\
\hline 4 & 47 & - & 11.2 & 1120 & 730 & 1140 & $\begin{array}{l}\text { mMTC; } \\
\text { mPTC }\end{array}$ & $\begin{array}{l}0.4 / 0.3 \\
0.2 / 0.15\end{array}$ & $\begin{array}{l}\text { PT1aN0; } \\
\text { PT1aNo }\end{array}$ \\
\hline 5 & 46 & II & 11.26 & 322.2 & 210.7 & 155.3 & PNG & - & - \\
\hline 6 & 37 & - & 11.57 & 131.5 & 92.25 & 67.21 & mPTC & $0.4 / 0.3$ & pT1aNx \\
\hline 7 & 54 & - & 11.8 & 182 & 151 & 108 & PNG & - & - \\
\hline 8 & 41 & - & 12.6 & 321 & 243 & 167 & mPTCm & $0.3 / 0.2+0.1 / 0.1$ & pT1amN0 \\
\hline 9 & 49 & - & 13.2 & 119 & 101 & 78 & mMTC & $0.2 / 0.1$ & pT1aNx \\
\hline 10 & 30 & ॥ & 13.7 & 289 & 478 & 430 & $\mathrm{CCH}$ & $0.05 / 0.01$ & - \\
\hline 11 & 35 & - & 13.72 & 393.4 & 295.5 & 222 & PTC & $3 / 2.3$ & pT2N0 \\
\hline 12 & 55 & - & 14 & 386 & 169 & 146 & $\begin{array}{l}\mathrm{mMTCm} \\
\mathrm{CCH}\end{array}$ & $\begin{array}{l}0.2 / 0.2+<0.1 \\
-\end{array}$ & $\begin{array}{l}\text { pT1amNx } \\
-\end{array}$ \\
\hline 13 & 61 & - & 14.08 & 33.16 & 29.91 & 32.36 & mPTCm & $<1 ;<1 ;<1$ & pT1am \\
\hline 14 & 42 & - & 14.15 & 270.6 & 190.1 & 121.9 & thyroiditis & - & - \\
\hline 15 & 53 & - & 14.33 & 127 & 111.3 & 81.49 & PTCm & $3.6 / 3+1.2 / 1+0.05 / 0.03$ & $\mathrm{pT} 2 \mathrm{mNO}$ \\
\hline 16 & 64 & - & 15.9 & 518 & 416 & 270 & mPTC & $0.6 / 0.4$ & PT1aNx \\
\hline 17 & 57 & - & 16.22 & 452.1 & 323.6 & 219.2 & $\begin{array}{l}\text { mMTCm; } \\
\text { NIFTP }\end{array}$ & $\begin{array}{l}0.5+0.1 \\
1.2\end{array}$ & $\begin{array}{l}\text { pT1amN0 } \\
-\end{array}$ \\
\hline 18 & 51 & - & 16.95 & 516.2 & 378.8 & 217.4 & mPTC & $0.05 / 0.04$ & pT1aNx \\
\hline 19 & 54 & - & 18.2 & 455 & 251 & 261 & PNG & - & - \\
\hline 20 & 49 & - & 18.33 & 266.2 & 210.9 & 160.1 & mPTCm & $0.2 / 0.2+0.1 / 0.1+0.06 / 0.03$ & pT1amN0 \\
\hline 21 & 46 & - & 18.86 & 307.7 & 215.6 & 148.8 & PNG & - & - \\
\hline 22 & 40 & - & 22.57 & 299.9 & 232.2 & 159.6 & mMTC & $0.5 / 0.4$ & pT1aNx \\
\hline 23 & 64 & - & 27.6 & 176 & 250 & 249 & thyroiditis & - & - \\
\hline 24 & 29 & - & 29.19 & 347.5 & 200.8 & 144.8 & $\mathrm{mMTCm}$ & $0.2+0.5$ & pT1amNo \\
\hline 25 & 51 & - & 29.5 & 96.6 & 98.1 & 82.1 & $\mathrm{mMTCm}$ & $<0.1+0.5 / 0.5$ & pT1amNx \\
\hline 26 & 54 & - & 29.93 & 382.9 & 303.4 & 198.2 & PTCm & $1.1 / 0.8+0.3 / 0.08$ & pT1bmN0 \\
\hline 27 & 66 & - & 33.08 & 96.54 & 123.6 & 110.9 & $\mathrm{mMTCm}$ & $0.6 / 0.5+0.2 / 0.5+0.15 / 0.15$ & pT1amNx \\
\hline 28 & 64 & II & 40.96 & 1713 & 1394 & 932.5 & mMTC & 0.56 & PT1aN0 \\
\hline 29 & 40 & - & 41.76 & 677.1 & 525.9 & 334.7 & $\begin{array}{l}\text { mMTC; } \\
\text { mPTC }\end{array}$ & $\begin{array}{l}0.6 / 0.5 \\
0.1 / 0.1\end{array}$ & $\begin{array}{l}\text { pT1aNo; } \\
\text { pT1aNo }\end{array}$ \\
\hline 30 & 65 & - & 60.13 & 724.6 & 460.4 & 414.7 & $\begin{array}{l}\text { mMTC; } \\
\text { mPTCm }\end{array}$ & $\begin{array}{l}0.9 / 0.7 \\
0.15 / 0.1+0.1 / 0.07\end{array}$ & pT1aN0; pT1amN0 \\
\hline 31 & 62 & - & 63.5 & 562 & 432 & 280 & $\begin{array}{l}\text { mMTC; } \\
\text { mPTC }\end{array}$ & $\begin{array}{l}0.7 / 0.6 \\
0.6 / 0.6\end{array}$ & $\begin{array}{l}\text { pT1aN0; } \\
\text { pT1aNo }\end{array}$ \\
\hline 32 & 63 & - & 66.1 & 1420 & 1040 & 696 & MTC & $1.2 / 1$ & pT1bNo \\
\hline 33 & 46 & - & 88.47 & 2812 & 2686 & 1735 & mMTC & $0.5 / 0.4$ & pT1aN0 \\
\hline 34 & 67 & II & 89 & 217 & 234.4 & 189.9 & $\begin{array}{l}\text { mMTCm; } \\
\text { mPTC }\end{array}$ & $\begin{array}{l}0.7 / 0.5+0.15 / 0.15 \\
0.1 / 0.1\end{array}$ & $\begin{array}{l}\text { PT1amN0; } \\
\text { PT1N0 }\end{array}$ \\
\hline 35 & 52 & - & 98.91 & 881.6 & 672.1 & 461.7 & MTC & 1.2 & pT1bNo \\
\hline
\end{tabular}

FNAB: Fine needle aspiration biopsy - Bethesda grading; bCT: Basal calcitonin; $2^{\prime}, 5^{\prime}, 10^{\prime}$ : Dosage of calcitonin after 2, 5 and 10 min after the end of calcium infusion; HP: Histopathological result; PTC: Papillary thyroid carcinoma; MTC: Medullary thyroid carcinoma; CCH: C-Cell hyperplasia; PNG: Polynodular goitre; mPTC: Micro-PTC $(<1 \mathrm{~cm})$; PTCm: Multifocal PTC; mMTC: Micro-MTC $(<1 \mathrm{~cm})$; MTCm: Multifocal MTC. 
- Table 2 Patients from group B (normal bCT) that had thyroidectomy $(n=31)$.

\begin{tabular}{|c|c|c|c|c|c|c|c|c|c|}
\hline No. & Age & $\begin{array}{l}\text { FNAB } \\
\text { (Bethesda) }\end{array}$ & $\begin{array}{l}\text { bCT } \\
\left(0^{\prime}\right)\end{array}$ & $\mathbf{2}^{\prime}$ & $5^{\prime}$ & $10^{\prime}$ & HP & Tumour Foci $(\mathrm{cm})$ & $\begin{array}{l}\text { Staging } \\
\text { system }\end{array}$ \\
\hline 1 & 47 & II & 0.5 & 1.02 & 0.69 & 0.5 & mPTC & $0.06 / 0.04$ & pT1aNx \\
\hline 2 & 67 & $\mathrm{~V}$ & 0.5 & 1.48 & 1.09 & 0.73 & PTC & $1.1 / 0.8$ & PT3NO \\
\hline 3 & 63 & - & 0.5 & 1.58 & 0.5 & 0.5 & mPTC & $0.4 / 0.3$ & pT1aNx \\
\hline 4 & 23 & IV & 0.5 & 1.89 & 1.43 & 1.01 & $\begin{array}{l}\text { follicular adenoma; } \\
\text { thyroiditis }\end{array}$ & - & - \\
\hline 5 & 51 & - & 0.5 & 2.49 & 2.23 & 2.15 & disembryoplastic cyst; PNG & - & - \\
\hline 6 & 26 & V & 0.5 & 1.05 & 2.56 & 2.77 & PTC & $4 / 2.5$ & PT3N1a \\
\hline 7 & 47 & - & 0.5 & 2.92 & 2.46 & 1.72 & mPTC; thyroiditis & $0.8 / 0.6$ & PT1aNo \\
\hline 8 & 51 & - & 0.5 & 3.25 & 1.76 & 1.49 & PNG & - & - \\
\hline 9 & 55 & - & 0.5 & 3.27 & 4.38 & 2.63 & follicular adenoma & - & - \\
\hline 10 & 72 & - & 0.5 & 1.62 & 4.54 & 2.8 & PNG; thyroiditis & - & - \\
\hline 11 & 44 & - & 0.5 & 3.59 & 1.93 & 5.08 & PNG & - & - \\
\hline 12 & 56 & - & 0.5 & 5.82 & 3.97 & 1.05 & PNG & - & - \\
\hline 13 & 68 & IV & 0.5 & 5.96 & 5.64 & 3.81 & mPTC & $0.1 / 0.1$ & pT1aNx \\
\hline 14 & 23 & - & 0.5 & 18.94 & 16.57 & 11.83 & follicular adenoma & - & - \\
\hline 15 & 69 & V & 0.61 & 3.55 & 2.74 & 1.7 & PTCm & $2 / 1.7+0.7 / 0.7$ & $\mathrm{pT} 2 \mathrm{mNx}$ \\
\hline 16 & 51 & - & 0.86 & 16.46 & 13.22 & 5.51 & PNG & - & - \\
\hline 17 & 55 & - & 1.08 & 20.23 & 19.28 & 14.77 & PTC & $3.5 / 3$ & pT2Nx \\
\hline 18 & 60 & - & 1.13 & 8.33 & 7.92 & 5.4 & follicular adenoma & - & - \\
\hline 19 & 26 & - & 1.13 & 1.21 & 26.6 & 14.96 & follicular adenoma & - & - \\
\hline 20 & 66 & - & 1.21 & 4.4 & 2.83 & 1.8 & PNG & - & - \\
\hline 21 & 35 & - & 1.22 & 0.5 & 3.27 & 4.19 & thyroiditis (Basedow) & - & - \\
\hline 22 & 28 & - & 1.32 & 21.75 & 17.68 & 13.66 & follicular adenoma & - & - \\
\hline 23 & 23 & ॥ & 1.33 & 1.22 & 1.36 & 1.02 & follicular adenoma & - & - \\
\hline 24 & 55 & - & 2.02 & 18.43 & 20.07 & 16.71 & PNG & - & - \\
\hline 25 & 46 & - & 2.2 & 20.12 & 14.96 & 5.33 & thyroiditis (Basedow) & - & - \\
\hline 26 & 43 & - & 2.25 & 19 & 15 & 13.6 & follicular adenoma & - & - \\
\hline 27 & 41 & - & 2.9 & 42.66 & 32.38 & 22.13 & mMTC & $0.6 / 0.6$ & pT1aN0 \\
\hline 28 & 78 & - & 3.96 & 20.7 & 20.3 & 17.4 & PNG & - & - \\
\hline 29 & 50 & V & 4.09 & 40.1 & 31.5 & 22.8 & PTCm; thyroiditis & $2 / 1.4+0.8 / 0.8$ & $\mathrm{pT} 3 \mathrm{mN} 1 \mathrm{~b}$ \\
\hline 30 & 50 & V & 6.44 & 138 & 120 & 101 & mPTCm & $0.3 / 0.2+<0.1$ & pT1amN0 \\
\hline 31 & 38 & - & 9.23 & 163 & 167 & 122 & PNG & - & - \\
\hline
\end{tabular}

FNAB: Fine needle aspiration biopsy - Bethesda grading; bCT: Basal calcitonin; 2', 5', 10': Dosage of calcitonin after 2,5 and 10 min after the end of calcium infusion; HP: Histopathological result; PTC: Papillary thyroid carcinoma; MTC: Medullary thyroid carcinoma; PNG: Polynodular goitre; mPTC: Micro-PTC $(<1 \mathrm{~cm})$; PTCm: Multifocal PTC; mMTC: Micro-MTC $(<1 \mathrm{~cm})$.

distinction between normal versus CCH and MTC cases [12]. Recently, updated Ca thresholds for bCT and sCT for MTC diagnosis of $>30 \mathrm{pg} /$ $\mathrm{ml}$ and $>79 \mathrm{pg} / \mathrm{ml}$ in females, respectively, $>34 \mathrm{pg} / \mathrm{ml}$ and $>466 \mathrm{pg} /$ $\mathrm{ml}$ in males were reported by Fugazzola and Mian's team [16].

Importantly, the variability of the assays must be taken into account $[1,12,25]$. Therefore, the identified cut-offs could change depending on the laboratory. More than that, the thresholds could vary depending on the population tested. That is why the current guidelines recommend that individual laboratories set their own reference thresholds [1]. To the best of our knowledge, we have identified for the first time for female Romanian population that the best bCT and Ca-sCT cut-offs able to distinguish MTC or CCH from other cases were above $12.9 \mathrm{pg} / \mathrm{ml}$ and $285.25 \mathrm{pg} / \mathrm{ml}$, respectively. Therefore, we recommend thyroid surgery in all women with sCT above $285 \mathrm{pg} / \mathrm{ml}$.

Establishing thresholds after stimulation tests may also be important for the diagnosis of differentiated thyroid carcinomas. Papadakis et al. also noticed that many patients with differentiated 


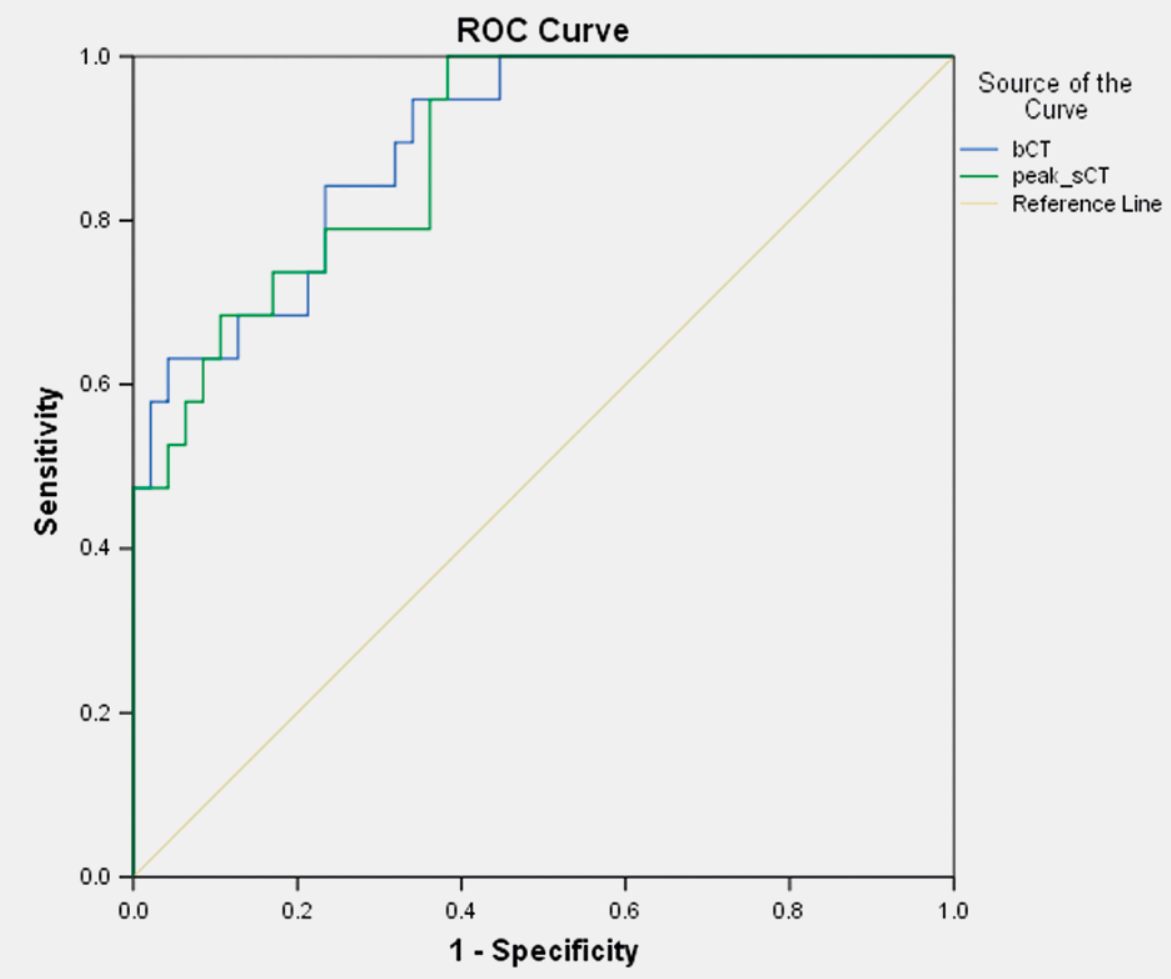

- Fig. 1 ROC curves for female cut-offs of basal and stimulated calcitonin.

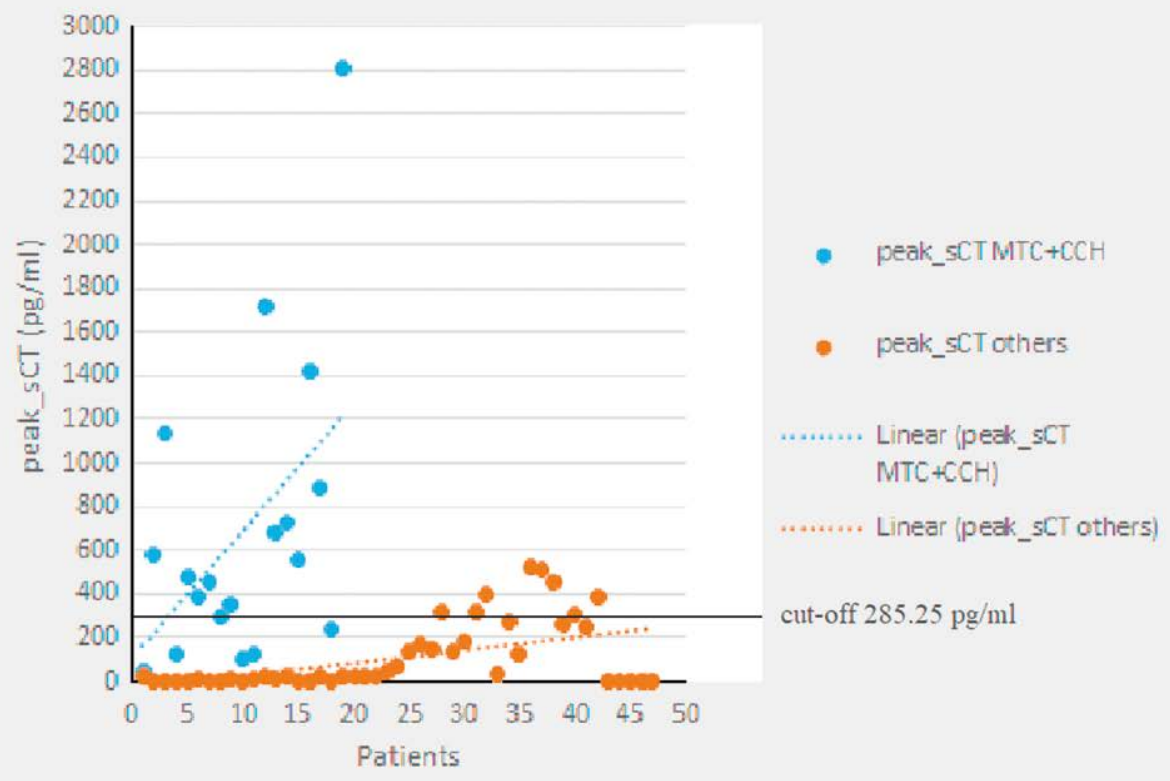

Fig. 2 Peak stimulated calcitonin - Medullary thyroid carcinoma and C-Cell hyperplasia vs. Others. 
thyroid carcinoma have sCT levels $>100 \mathrm{pg} / \mathrm{ml}$ [15]. Interestingly, in our study, the bCT cut-off remained the same if we wanted to distinguish female patients with either MTC, CCH or macroPTC from other cases, with a lower sensitivity of $70.4 \%$ and greater specificity of $79.5 \%$, a lower AUC 0.79 (Cl: 0.674-0.906), $\mathrm{p}<0.001$. The sCT cut-off lowered to $36.63 \mathrm{pg} / \mathrm{ml}$ if we wanted to distinguish female patients with either MTC, CCH or macro-PTC, with a greater sensitivity of $85.2 \%$ and a lower specificity of $61.5 \%$, a lower AUC 0.772 (Cl: $0.651-0.893), p<0.001$. The fact that AUC lowers under 0.8 suggests that this could be a fair test and could have some uses in diagnosing macro-PTC, but not very reliable.

Regarding the safety, short-lasting mild to moderate side effects were reported in literature during Ca stimulation tests [12, 14, 16, 20-22, 26]. Ubl et al. published gender differences concerning the adverse reactions after Ca infusion [27]. Dizziness and urgency to micturate were more frequent in women, whereas nausea, vomiting, altered taste and abdominal cramping were less frequent in women comparing to men [27]. In our study, 99 patients experienced 14 types of side-effects, the most frequent being the feeling of warmth (in $92.79 \%$ explorations), metallic taste (in $15.31 \%$ explorations) followed by nausea and dizziness (in $5.4 \%$ explorations). Bradycardia was noted in 4 explorations (3.6\%), while tachycardia, angina, atrial and ventricular extrasystoles each in an exploration $(0.9 \%)$. The occurrence of cardiovascular side-effects was not correlated with the value of bCT (elevated or normal), nor with the peak values of sCT. No life-threatening side effects were recorded in our female group, and in our experience so far, men are more prone to develop cardio-vascular adverse events than women: bradycardia, tachycardia, ventricular or atrial extrasystoles, asystole, hypertension, hypotension, or angina $(p=0.02)$ (unpublished data). Even though serious cardiac adverse events are rare, and they appear mostly in the first 5 minutes after $\mathrm{Ca}$ infusion, the patients should remain in observation another 60-180 minutes after the end of the test for monitoring.

It is important to further monitor these patients from our study to determine if Ca stimulation test has also applicability in predicting the prognosis, as others have shown with $\mathrm{Pg}$ stimulation test [28]. Regarding the prognosis, it is clear that the stage of MTC at the time of diagnosis is an essential factor. In our hypercalcitoninaemia group, among 35 female patients to whom surgery was recommended, 23 were diagnosed with micro-tumours and 5 with macro-tumours, hence the detection was in early stages. After surgery, CT was undetectable for 15 out of 18 patients diagnosed with MTC, and for the rest of 3 it is unknown yet in follow-up. Therefore, we recommend the routine $\mathrm{CT}$ measurement in the thyroid nodules protocol and to perform the Ca stimulation test when CT is elevated for an early diagnosis of malignancy. Current data demonstrates the potency of Ca-CT stimulation test for the diagnosis of MTC.

\section{Conclusions}

We have identified for the first time in Romanian female population bCT and SCT thresholds to discriminate MTC or CCH from other cases. We recommend thyroid surgery in all women with $\mathrm{SCT}$ above $285 \mathrm{pg} / \mathrm{ml}$. Further studies on larger groups are necessary to estab- lish and confirm male and female cut-offs for early diagnosis of MTC, and interestingly, maybe for macro-PTC alike. The Ca administration has minimum side-effects, but continuous cardiac monitoring is recommended. The present data that proves the potency of Ca stimulation test, along with the availability and low cost of Ca, advocate that the Ca CT stimulation test should be standardized and applied.

\section{Conflict of Interest}

The authors declare that they have no conflict of interest.

\section{References}

[1] Wells SA, Asa SL, Dralle H et al. Revised American thyroid association guidelines for the management of medullary thyroid carcinoma. Thyroid 2015; 25: 567-610

[2] Vierhapper H, Raber W, Bieglmayer C et al. Routine measurement of plasma calcitonin in nodular thyroid diseases. J Clin Endocrinol Metab 1997; 82: 1589-1593

[3] Costante G, Meringolo D, Durante C et al. Predictive value of serum calcitonin levels for preoperative diagnosis of medullary thyroid carcinoma in a cohort of 5817 consecutive patients with thyroid nodules. J Clin Endocrinol Metab 2007; 92: 450-455

[4] Pacini F, Fontanelli M, Fugazzola L et al. Routine measurement of serum calcitonin in nodular thyroid diseases allows the preoperative diagnosis of unsuspected sporadic medullary thyroid carcinoma. J Clin Endocrinol Metab 1994; 78: 826-829

[5] Rieu M, Lame MC, Richard A et al. Prevalence of sporadic medullary thyroid carcinoma: The importance of routine measurement of serum calcitonin in the diagnostic evaluation of thyroid nodules. Clin Endocrinol (Oxf) 1995; 42: 453-460

[6] Hahm JR, Lee MS, Min YK et al. Routine measurement of serum calcitonin is useful for early detection of medullary thyroid carcinoma in patients with nodular thyroid diseases. Thyroid 2001; 11: 73-80

[7] Chambon G, Alovisetti C, Idoux-Louche C et al. The use of preoperative routine measurement of basal serum thyrocalcitonin in candidates for thyroidectomy due to nodular thyroid disorders: Results from 2733 consecutive patients. J Clin Endocrinol Metab 2011; 96: 75-81

[8] Băetu M, Dobrescu R. Novel markers for early diagnosis and prognostic classification in medullary thyroid carcinoma. Acta Endocrinol (Buchar) 2017; 13: 519-522

[9] Elisei R. Routine serum calcitonin measurement in the evaluation of thyroid nodules. Best Pract Res Clin Endocrinol Metab 2008; 22: 941-953

[10] Haugen BR, Alexander EK, Bible KC et al. 2015 American thyroid association management guidelines for adult patients with thyroid nodules and differentiated thyroid cancer: the American thyroid association guidelines task force on thyroid nodules and differentiated thyroid cancer. Thyroid 2016; 26: 1-133

[11] Rosario PW, Mourão GF, Calsolari MR. Usefulness of serum calcitonin in patients with thyroid nodules $\leq 1 \mathrm{~cm}$ without an indication for fine-needle aspiration. Horm Metab Res 2020; 52: 216-219

[12] Colombo C, Verga U, Mian C et al. Comparison of calcium and pentagastrin tests for the diagnosis and follow-up of medullary thyroid cancer. J Clin Endocrinol Metab 2012; 97: 905-913

[13] Giovanella L. Serum procalcitonin and calcitonin normal values before and after calcium gluconate infusion. Exp Clin Endocrinol Diabetes 2012; 120: 169-170 
[14] Mian C, Perrino M, Colombo C et al. Refining calcium test for the diagnosis of medullary thyroid cancer: cutoffs, procedures, and safety. J Clin Endocrinol Metab 2014; 99: 1656-1664

[15] Papadakis G, Keramidas I, Triantafillou E et al. Association of basal and calcium-stimulated calcitonin levels with pathological findings after total thyroidectomy. Anticancer Res 2015; 35: 4251-4258

[16] Fugazzola L, Di Stefano M, Censi S et al. Basal and stimulated calcitonin for the diagnosis of medullary thyroid cancer: Updated thresholds and safety assessment. J Endocrinol Invest 2020; 44: 587-597

[17] Machens A, Hoffmann F, Sekulla C et al. Importance of gender-specific calcitonin thresholds in screening for occult sporadic medullary thyroid cancer. Endocr Relat Cancer 2009; 16: 1291-1298

[18] Guyétant S, Rousselet MC, Durigon M et al. Sex-related C cell hyperplasia in the normal human thyroid: A quantitative autopsy study. J Clin Endocrinol Metab 1997; 82: 42-47

[19] Medullary thyroid cancer: Surgical treatment and prognosis - up to date n.d. https://www.uptodate.com/contents/medullary-thyroid-cancer-surgical-treatment-and-prognosis; accessed December 19, 2020

[20] Doyle P, Düren C, Nerlich K et al. Potency and tolerance of calcitonin stimulation with high-dose calcium versus pentagastrin in normal adults. J Clin Endocrinol Metab 2009; 94: 2970-2974

[21] Thiem U, Marculescu R, Cejka D et al. Low-dose calcium versus pentagastrin for stimulation of calcitonin in chronic hemodialysis patients: A pilot study. J Clin Endocrinol Metab 2014; 99: 4704-4711

[22] Băetu M, Olariu CA, Moldoveanu G et al. Calcitonin stimulation tests: rationale, technical issues and side effects: A review. Horm Metab Res 2021; 53: 355-363
[23] Kihara M, Miyauchi A, Kudo T et al. Reference values of serum calcitonin with calcium stimulation tests by electrochemiluminescence immunoassay before/after total thyroidectomy in Japanese patients with thyroid diseases other than medullary thyroid carcinoma. Endocr J 2016; 63: 627-632

[24] Kihara M, Miyauchi A, Kudo T et al. Serum calcitonin reference values for calcium stimulation tests by electrochemiluminescence immunoassay in Japanese men with non-medullary thyroid carcinoma. Surg Today 2017; 48: 223-228

[25] Băetu M, Drăghici A, Pădure A et al. Correction factor between two calcitonin assays: DiaSorin LiaisonXL and Cobas E601. Rev Rom Med Lab 2021; 29: 271-276

[26] Vainas I, Marthopoulos A, Chrisoulidou A et al. Calcitonin stimulation tests for the early diagnosis and follow-up of patients with $C$ cell disease: A descriptive analysis. Hippokratia 2013; 17: 246-251

[27] Ubl P, Gincu T, Keilani M et al. Comparison of side effects of pentagastrin test and calcium stimulation test in patients with increased basal calcitonin concentration: The gender-specific differences. Endocrine 2014; 46: 549-553

[28] Machens A, Hauptmann S, Dralle H. Medullary thyroid cancer responsiveness to pentagastrin stimulation: An early surrogate parameter of tumor dissemination? J Clin Endocrinol Metab 2008; 93 : $2234-2238$ 